\title{
The importance of sample size in marine megafauna tagging studies
}

\author{
A. M. M. Sequeira, ${ }^{1,17}$ M. R. Heupel,${ }^{2}$ M.-A. Lea, ${ }^{3}$ V. M. Eguíluz, ${ }^{4}$ C. M. Duarte,${ }^{5}$ M. G. Meekan, ${ }^{6}$ M. Thums, ${ }^{6}$ \\ H. J. Calich, ${ }^{7}$ R. H. Carmichael, ${ }^{8}$ D. P. Costa, ${ }^{9}$ L. C. Ferreira, ${ }^{6}$ J. Fernandéz-Gracia, ${ }^{4}$ R. Harcourt, ${ }^{10}$ \\ A.-L. Harrison, ${ }^{11}$ I. Jonsen, ${ }^{10}$ C. R. McMahon, ${ }^{10,12}$ D. W. Sims, ${ }^{13,14}$ R. P. Wilson, ${ }^{15}$ And G. C. Hays ${ }^{16}$ \\ ${ }^{1}$ IOMRC and The University of Western Australia Oceans Institute, School of Biological Sciences, University of Western Australia, 35 \\ Stirling Highway, Crawley, Western Australia 6009 Australia \\ ${ }^{2}$ Australian Institute of Marine Science, PMB No 3, Townsville, Queensland 4810 Australia \\ ${ }^{3}$ Institute for Marine and Antarctic Studies, University of Tasmania, 20 Castray Esplanade, Hobart, Tasmania 7000 Australia \\ ${ }^{4}$ Instituto de Física Interdisciplinar y Sistemas Complejos IFISC (CSIC - UIB), E-07122 Palma de Mallorca, Spain \\ ${ }^{5}$ Red Sea Research Centre (RSRC), King Abdullah University of Science and Technology, Thuwal 23955-6900 Saudi Arabia \\ ${ }^{6}$ Australian Institute of Marine Science, Indian Ocean Marine Research Centre (M096), University of Western Australia, 35 Stirling \\ Highway, Crawley, Western Australia 6009 Australia \\ ${ }^{7}$ IOMRC and The University of Western Australia Oceans Institute, Oceans Graduate School, University of Western Australia, 35 \\ Stirling Highway, Crawley, Western Australia 6009 Australia \\ ${ }^{8}$ Dauphin Island Sea Lab and University of South Alabama, 101 Bienville Boulevard, Dauphin Island, Alabama 36528 USA \\ ${ }^{9}$ Department of Ecology and Evolutionary Biology, University of California, Santa Cruz, California 95060 USA \\ ${ }^{10}$ Department of Biological Sciences, Macquarie University, Sydney, New South Wales 2109 Australia \\ ${ }^{11}$ Migratory Bird Center, Smithsonian Conservation Biology Institute, National Zoological Park, PO Box 37012 MRC 5503 MBC, \\ Washington, D.C. 20013 USA \\ ${ }^{12}$ Sydney Institute of Marine Science, 19 Chowder Bay Road, Mosman, 2088 New South Wales, Australia \\ ${ }^{13}$ Marine Biological Association of the United Kingdom, The Laboratory, Citadel Hill, Plymouth PL1 2PB United Kingdom \\ ${ }^{14}$ Ocean and Earth Science, National Oceanography Centre Southampton, Waterfront Campus, University of Southampton, \\ Southampton SO14 3ZH United Kingdom \\ ${ }^{15}$ Department of Biosciences, Swansea University, Swansea, United Kingdom \\ ${ }^{16}$ Deakin University, Geelong, Victoria, Australia
}

Citation: Sequeira, A. M. M., M. R. Heupel, M.-A. Lea, V. M. Eguíluz, C. M. Duarte, M. G. Meekan, M. Thums, H. J. Calich, R. H. Carmichael, D. P. Costa, L. C. Ferreira, J. Fernandéz-Gracia, R. Harcourt, A.-L. Harrison, I. Jonsen, C. R. McMahon, D. W. Sims, R. P. Wilson, and G. C. Hays. 2019. The importance of sample size in marine megafauna tagging studies. Ecological Applications 00(00):e01947. 10.1002/eap.1947

Abstract. Telemetry is a key, widely used tool to understand marine megafauna distribution, habitat use, behavior, and physiology; however, a critical question remains: "How many animals should be tracked to acquire meaningful data sets?" This question has wide-ranging implications including considerations of statistical power, animal ethics, logistics, and cost. While power analyses can inform sample sizes needed for statistical significance, they require some initial data inputs that are often unavailable. To inform the planning of telemetry and biologging studies of marine megafauna where few or no data are available or where resources are limited, we reviewed the types of information that have been obtained in previously published studies using different sample sizes. We considered sample sizes from one to $>100$ individuals and synthesized empirical findings, detailing the information that can be gathered with increasing sample sizes. We complement this review with simulations, using real data, to show the impact of sample size when trying to address various research questions in movement ecology of marine megafauna. We also highlight the value of collaborative, synthetic studies to enhance sample sizes and broaden the range, scale, and scope of questions that can be answered.

Key words: animal welfare; key questions; movement behavior; number of tags; telemetry studies; tracking data.

\section{INTRODUCTION}

Tracking studies of marine animals have proliferated in recent years as a new generation of miniaturized, cost-effective, and reliable telemetry tags are deployed on an

Manuscript received 8 December 2018; revised 10 April 2019; accepted 17 April 2019. Corresponding Editor: Nigel Edward Hussey.

${ }^{17}$ E-mail: ana.sequeira@uwa.edu.au ever-increasing array of species (Fig. 1; Evans et al. 2013). These technological advances have led to a dramatic increase in the use of the Argos and GPS satellite systems to track highly migratory marine vertebrates. Including the large-bodied marine megafauna, that surface to breathe or spend time on land enabling transmitters to communicate with satellites. Simultaneously, an expansion of acoustic telemetry networks to track gill-breathing animals that remain submerged, like tunas or sharks, has 


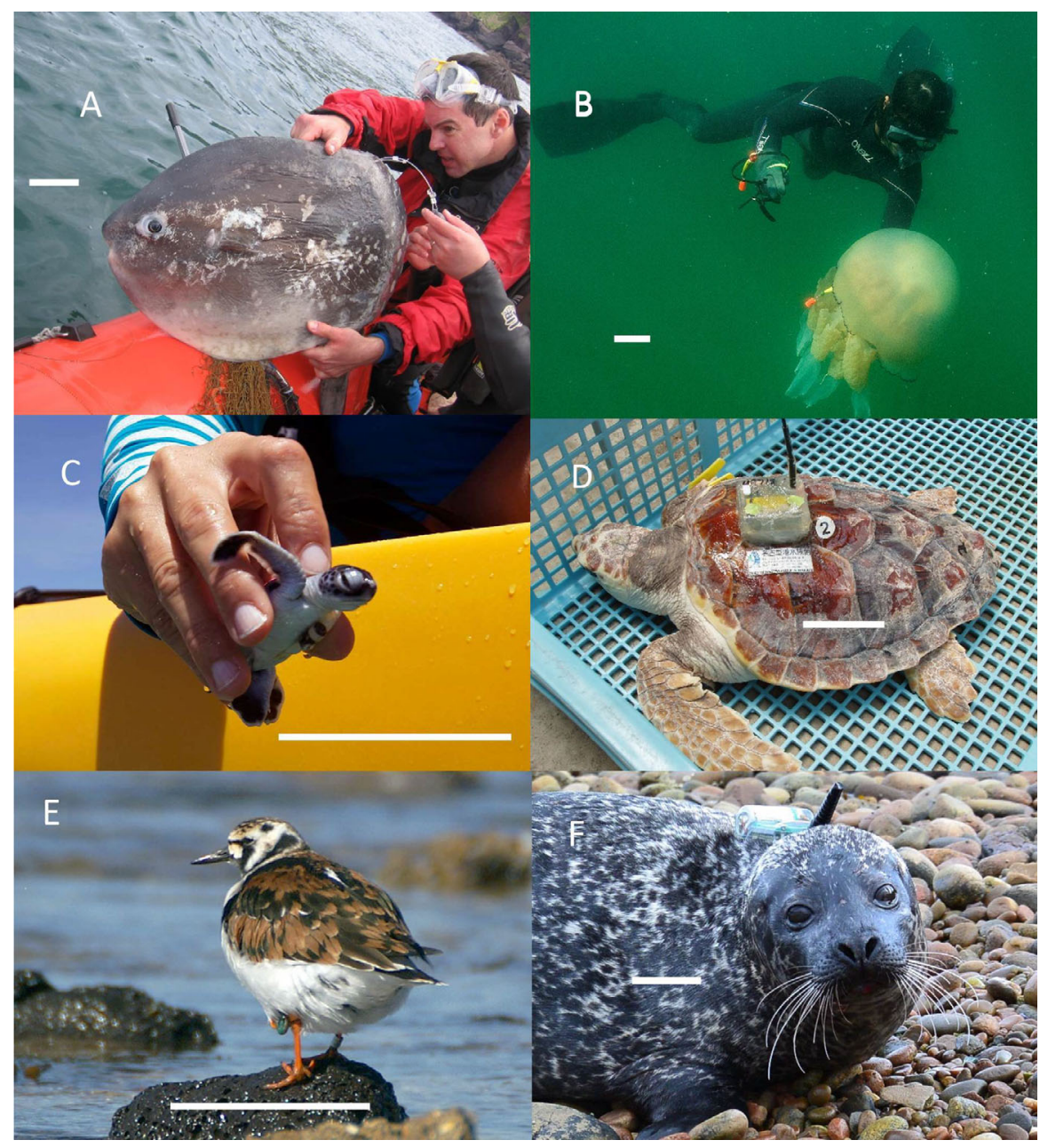

FIG. 1. Across a broad range of species and habitats, electronic tags are used to assess patterns of animal movement. Across studies, a prevailing question is "how many animals need to be tagged?" To illustrate the breadth of tracking studies, this figure shows (A) an ocean sunfish (Mola mola) fitted with a satellite tag, (B) a jellyfish (Rhizostoma octopus) equipped with a time-depth recorder, (C) a hatchling green turtle (Chelonia mydas) equipped with a miniature acoustic tag, (D) a juvenile loggerhead sea turtle (Caretta caretta) equipped with an Argos satellite tag, (E) a ruddy turnstone (Arenaria interpres) equipped with a light-based geolocator tag on its leg, and (F) a harbor seal (Phoca vitulina) with a "mobile phone tag" that relays Fastloc-GPS locations via the mobile phone network. In each panel the scale bar is $10 \mathrm{~cm}$. Photographs courtesy of Graeme Hays, Gower Coast Adventures, Joan Costa, George Balazs, Erik Kleyheeg, and Paul Thompson.

occurred. These advances also have been coupled with an increasing diversity in the sensors available on tags and other bio-logging devices (Hebblewhite and Haydon 2010, Hussey et al. 2015, Kays et al. 2015). Combined with advanced analytical techniques, these technological innovations have transformed our knowledge of movement patterns, behavior, habitat use, and ecophysiology of animals with movement data driving a series of positive conservation outcomes across multiple taxa such as the creation of marine protected areas and other conservation zones (Hays, 2019, 983). However, the deployment of tags can involve procedures that stress the target animals (Wilson and McMahon 2006), including capture and restraint, anesthesia, chemical immobilization, and surgery (Harcourt et al. 2010). Further, costs and logistics associated with purchase and deployment of tags are considerable.
For example, satellite-linked Argos tags cost several thousand US\$ per unit with on-going operational costs for satellite time. Consideration of these various elements leads to a fundamental but complex question: what is the minimum number of animals that should be tagged and tracked for a given study to deliver sufficient data to address the research aims (Wilson and McMahon 2006, Hays et al. 2016), while ensuring the number of animals tagged complies with ethical pillars of the three R's of Reduce, Replace, and Refine (Russell and Burch 1959)?

There are well-established metrics to determine sample size and provide the statistical power necessary to draw probability-based conclusions from data sets (Green 1989, Johnson et al. 2015). Hence, answering the question of how many tags to deploy in any given study would seem straightforward. However, power analyses 
require some initial data or knowledge of the expected movements of animals, such as on the variance of the behavior being studied, or on the movement range. This information is often not available because researchers are studying new species or working in new areas. Furthermore, an important caveat to the application of power analyses is that many of these studies are still in the "discovery" phase and the most interesting or relevant questions or observations are still unknown. Although it is always prudent to undertake power analyses when possible, here, we take a complementary approach to assist the planning of telemetry and biologging studies of marine megafauna where little or no prior data are available. We focus on marine megafauna and satellite tracking, given the growth of this area, but some of our conclusions are relevant to other biologging approaches. For example, data storage tags that measure parameters such as diving and body acceleration are widely deployed on marine megafauna and the increasing use of acoustic arrays, often in networks spanning thousands of kilometers (Lennox et al. 2017), means that acoustic tags are also widely used within this group including smaller life stages of some taxa, such as hatchling sea turtles (Thums et al. 2013). We do not focus on smaller bodied, commercial species because there are complexities associated with sample size for this size range that need separate consideration, for example their common fine-scale stock structure (Righton et al. 2007). Here, we review the types of information that have been obtained by studies with different sample sizes of marine megafauna (Fig. 2). In doing so, we provide guidance for researchers embarking on tracking studies of marine megafauna by summarizing what has been achieved with sample sizes from one to well over 100 individuals. We provide examples of simulation exercises that can be used to estimate the sample size needed to address specific questions. We show evidence that significant advances can be made with small sample sizes while highlighting the benefits obtained from employing greater sample sizes and supplement this review with simulations from real data to illustrate how the ability to answer specific research questions changes with the sample size of tracked individuals. We illustrate this, showing how different sample sizes are needed when addressing different questions of interest for the same taxa (using turtles as example), and also when addressing the same question (using home range or utilization area as example) for multiple taxa (sharks, seabirds, seals). We also highlight the value of data sharing and showcase some of the seminal discoveries made by combining data across studies to reach very large sample sizes.

The value of different sample sizes is best exemplified in work from individuals who pioneered tagging on the same system or species, necessarily starting with small numbers of tags before attaining larger sample sizes that altered the scope of their work allowing new questions to be addressed. For example, a thread of work tracking leatherback turtles in the Atlantic began with $n=3$ (Hays et al. 2004a), progressed to $n=21$ (Fossette et al. 2010), then $n=106$ (Fossette et al. 2014) to recently become part of a study involving $>2,500$ tracked marine animals across multiple species (Sequeira et al. 2018). At each iteration, the questions that were addressed changed, and this increasing capability is reflected in the synthesis presented here.

\section{Dare to Dream (Sample Size of One)}

Many researchers assert that tracking studies with sample sizes of one are of no value, but the history of animal tracking includes many startling discoveries made from tracking one individual. While, statistically, a sample size of one is expected to capture a "normal" or common trajectory, the value of such studies actually lies in their ability to show that certain feats are possible. Examples of extraordinary feats detected in single animal studies include the journey of $>1,000 \mathrm{~km}$ by a leatherback turtle (Dermochelys coriacea) tagged off South Africa (Hughes et al. 1998), and the discovery that white sharks (Carcharodon carcharias) can last more than a month on a single large meal (Carey et al. 1982, but see Semmens et al. 2013). Additionally, despite multiple tags having been used in another white shark study, it was the track from a single white shark traversing an entire ocean basin while performing deep dives to nearly $1,000 \mathrm{~m}$ (combined with photo ID data) that was central to the discovery that these sharks are not coastal obligates (Bonfil et al. 2005). A single tagged sea turtle was also found to routinely conduct sequences of dives each $6-8 \mathrm{~h}$ followed by short interdive surface intervals suggesting operation within its aerobic dive limit and fundamentally altering the expectations of the ecophysiological capacity for this species (Hochscheid et al. 2005). Individual tracks can also provide significant information with conservation implications. For example, the track of a single grey whale (Eschrichtius robustus) tagged within the feeding grounds of the critically endangered western stock off Sakhalin Island, Russia, and migrating to the breeding lagoons of the eastern stock in Baja California, Mexico, questioned whether these two stocks were indeed distinct (Mate et al. 2015). This individual whale also broke the world record (previously held by a humpback whale) for the longest known mammalian migration at $22,511 \mathrm{~km}$.

Data from one individual can also reveal aspects of behavior linked to physical abilities and, if sampled at very high frequency, they can provide high-resolution movement information. For example, flipper sensors attached to a turtle revealed how swimming effort was linked to depth-dependent, air-mediated buoyancy and swim angle (Hays et al. 2004c). Finally, and importantly, a sample size of one may provide critical proof of concept for novel equipment or attachment procedures, providing a starting point for follow-up studies. For example, one of the first animals tracked by Argos 


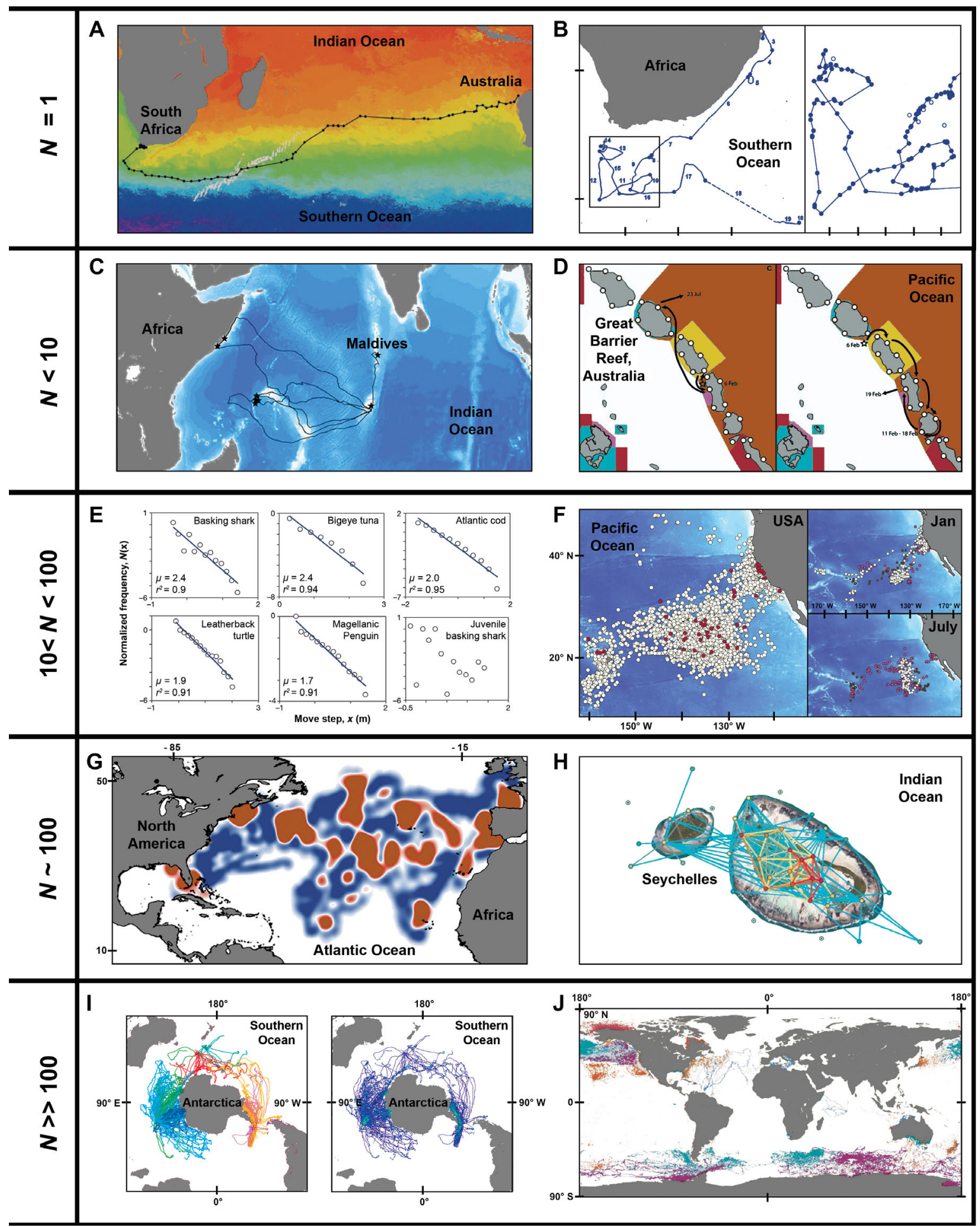

satellite-linked tags was a plankton-feeding basking shark (Cetorhinus maximus) that oriented along thermal fronts for $17 \mathrm{~d}$ (Priede 1984). The species was studied further with increasing numbers of tags providing insight into other ecologically relevant questions (Sims et al. 2003, 2005, Southall et al. 2006).
As animal-borne tags are increasingly used to obtain data on the environment, single tags can also provide highly valuable data that would be difficult to obtain with any other observing system. For example, the use of a CTD (conductivity, temperature, and depth) tag on a single southern elephant seal (Mirounga leonina) provided an 
FIG. 2. Examples of tracking studies using various sample sizes to understand different animal movement and behaviors. (A) Track of a great white shark showing a transoceanic migration from South Africa to northwestern Australia; color indicates average sea surface temperature ranging from $-7.6^{\circ} \mathrm{C}$ (indigo) to $32.5^{\circ} \mathrm{C}$ (red) (adapted from Bonfil et al. 2005). (B) Track from a leatherback turtle revealing that the species was able to travel thousands of kilometers (adapted from Hughes et al. 1998). (C) Tracked movement of eight green turtles equipped off Diego Garcia, Chagos, used to evaluate effectiveness of marine protected areas in the region (adapted from Hays et al. 2014b). (D) Movements of grey reef sharks in the Great Barrier Reef, Australia, showing site fidelity to single reefs; white circles: acoustic receiver locations; brown polygon: buffer zone; white, teal, yellow, pink and red polygons: different management zones (adapted from Heupel et al. 2010). (E) Comparison of vertical movement patterns of basking sharks, bigeye tuna, Atlantic cod, leatherback turtles, Magellanic Penguins, and juvenile basking sharks across taxa showing levy-like scaling laws (plots shown on $\log _{10}$ scale; adapted from Sims et al. 2008); (F) Satellite tag location estimates from great white sharks tagged along the central California coast, showing patterns of site fidelity and seasonal variations in movements. Left: white shows geolocation position estimates; red shows Argos satellite end point positions. Right: position estimates of male (white), female (purple), and unsexed (dark grey) white sharks (adapted from Jorgensen et al. 2010). (G) Habitat use patterns of pelagic sharks in the North Atlantic Ocean, used to examine key areas of spatial overlap with longline fisheries; orange and blue shading indicates regions of hotspots and coldspots, respectively, for satellite-tracked pelagic sharks (adapted from Queiroz et al. 2016). (H) Networks of species-specific detections obtained from passive acoustic tracking of blacktip reef sharks, used to evaluate and subsequently update a marine protected area in the Seychelles; colors indicate the detection frequency and connectivity between nodes, ranging from low (blue) to high (red), receivers with no detections are indicated in white with a black dot in the center (adapted from Lea et al. 2016). (I) Trajectories obtained for 272 southern elephant seals (left) and resulting occupancy map (right), used to identify movement patterns that indicated memory may play a role in the movement patterns of this species. Left: different colors indicate the trajectories of animals tagged at seven locations. Right: high (green) to low (indigo) occupancy of elephant seals on a logarithmic scale (adapted from Rodriguez et al. 2017). (J) Global map of tracking data set used to quantify the movement patterns of $>50$ marine vertebrate species, showing that movement patterns are strongly conserved across species and vary based on the habitats the animals move through; line colors show different tracks for 50 marine megafauna species (adapted from Sequeira et al. 2018).

8-month hydrographic profile that allowed an assessment of the seasonal evolution of the upper ocean (Meredith et al. 2011). Similarly, a CTD tagged Weddell seal (Leptonychotes weddellii) provided some of the first data on the wintertime conditions over the Weddell Sea continental shelf (Nicholls et al. 2008). Indeed, marine mammals and particularly seals, now provide the bulk of the physical oceanographic observations in the polar regions and are a central component of the global ocean observing system (Treasure et al. 2017). Despite the common perception of the limited value of a sample size of one, the examples above show evidence that even a single tag can provide ground-breaking information allowing insights into population- and species-level ecology and guiding future studies.

\section{Understanding Variability (Sample Sizes up to 10)}

As sample sizes increase, so too does the probability that tags will reveal individual variability in the behavior being observed. Statements based on such data can move from possible limits of animal performance to plausible and ecologically valuable metrics for the species, such as diving behavior, home ranges, and foraging areas. Variations in individual foraging patterns have been observed with surprisingly small sample sizes. For example, three distinct foraging patterns were detected in data derived from nine Galapagos sea lions (Zalophus wollebaeki; Villegas-Amtmann et al. 2008), which were, in subsequent studies, correlated with differences in the physiological capability of these animals (Villegas-Amtmann and Costa 2010). Sample sizes of only a few individuals may also be immensely valuable when high-resolution temporal data are available. This is the case for diving data of marine vertebrates downloaded from the archive of recovered tags that are equipped with pressure sensors (e.g., SPLASH tags, pop-off satellite-linked archival transmitters [PSAT], and dive loggers), which allow for greater insight into the environmental and physiological drivers of movement patterns (Deutsch et al. 2003, Meekan et al. 2015). This type of high-resolution temporal data is more easily collected for animals that return to areas that are predictable in space and time (e.g., breeding areas) and thus facilitate tag recovery. This is because the data that are transmitted to satellite are binned summaries only and the detailed patterns of vertical movements are only available in the tag archives. So, for animals that do not return to breeding or over-wintering sites, such as whale sharks (Rhincodon typus), the detailed patterns of vertical movements can only be obtained when detached tags are recovered by chance (e.g., when these sharks wash up on beaches). Such limitations to data acquisition, in addition to problems with tag failure and loss, need to be factored into the initial sample size of tags. Therefore, information on the expected return of data from all animals tagged is important when writing ethics approvals, to estimate the cost of the project and to define the research scope.

Although larger sample sizes typically are recommended for many ecological questions, a sample size of up to 10 individuals may be immensely valuable for some applications. For example, when testing and developing new methods or technologies, deploying $>10$ tags may lead to potentially unforeseen negative impacts on animals and waste financial resources. A sample size $\leq 10$ may also be appropriate when studying critically endangered species. Indeed, in such cases, the limit of $\leq 10$ might be enforced by permitting agencies. When generating hypotheses about unknown phenomena, a sample size of up to 10 tags could also be a good starting point, allowing this exploration phase to dictate if the phenomenon is worth exploring further. Also a sample size of $\leq 10$ may be appropriate for species or questions that are difficult to study, such as following social groups on long migrations, or where high logistics costs for deployment may limit funds available for tags, as is the case, for 
instance, for killer whales (Orcinus orca; Durban and Pitman 2012).

An early example of the value of relatively small sample sizes is a satellite tagging study of six Wandering Albatrosses (Diomedea exulans), which revealed individuals travelling thousands of kilometers in a single foraging trip during an incubation shift in the southwestern Indian Ocean (Jouventin and Weimerskirch 1990). Although such a small data set might not provide sufficient precision to determine preferred foraging areas, the consistency of the distances covered provoked a fundamental shift in how researchers thought about habitat use by these birds. Similarly, for $50 \mathrm{yr}$, basking sharks were thought to hibernate in deep waters of the North Atlantic Ocean during winter until satellite tracking of five individuals showed that they exhibit extensive horizontal and vertical movements at this time (Sims et al. 2003).

As sample size increases, variability in space use can be defined in more detail. For example, while a study of nine leatherback turtles in the Atlantic Ocean revealed individuals all moving in disparate directions (Hays et al. 2004b), the majority of nine grey reef sharks (Carcharhinus amblyrhynchos) in the Great Barrier Reef, Australia, showed fidelity to a single reef, while one individual undertook a 134-km movement across the deep open ocean (Heupel et al. 2010). Inclusion of nine individuals in the latter study indicated that although large movements were present, they were not representative. In contrast, the former study indicated that a larger sample size is required to fully understand patterns in movement for leatherback turtles.

When a study species is rare or endangered, small sample sizes are unavoidable, but their value is amplified because they may represent a larger proportion of the population (McMahon and Hays 2006). However, the scope of questions that can be addressed for such species through tracking and biologging are likely to be constrained by low sample sizes. Sample sizes of approximately 10 tagged individuals have been useful in identifying responses to environmental variation, and possible drivers of movement of some species. For example, the diving behavior of 10 satellite-tracked female Antarctic fur seals (Arctocephalus gazella) highlighted their differential use of oceanographic features (Lea and Dubroca 2003). Insights into size- or sex-based differences in behavior can also become evident. For example, active acoustic tracking of only two male and two female benthic catsharks during a 14-d period (Sims et al. 2001) suggested sexual segregation by habitat. This result stimulated further studies that revealed the mechanisms underlying these sex differences in behavioral patterns (Wearmouth et al. 2012).

To further exemplify how small sample sizes can lead to insightful sex-based differences in marine megafauna, we used a simulation exercise to explore how differences in breeding periodicity between male and female turtles can be detected with even small increments in sample size. Understanding these differences in breeding periodicity is important because turtles have temperature-dependent sex determination, and the rising incubation temperatures due to climate change will likely produce increasingly sex ratios skewed toward females. For our simulation, we used information published in a recent study for loggerhead turtles (Caretta caretta) in the Mediterranean, where males tend to return to breed after $1 \mathrm{yr}$ with probability of $0.76\left(p_{\text {male }}=0.76\right)$ whereas females returned after longer intervals (i.e., the probability of returning to breed after $1 \mathrm{yr} p_{\text {female }}=0.00$; Hays et al. 2014a). These probabilities were originally based on tracks from 25 individuals (17 males and 8 females) but we use them here to show the likelihood of the same biological conclusion being reached with smaller sample sizes. Using these probabilities, and assuming equal numbers of tracked males and females, we ran 1,000 simulations for sample sizes ranging from one to eight female and male individuals, randomly selecting the number of males and females that would be recorded to return after $1 \mathrm{yr}$. When only three males and three females were tracked, the probability of recording a significant difference in numbers returning was only 0.331 , but this rose to 0.983 when eight females and eight males were tracked (Fig. 3A). This simulation exercise illustrates how researchers can use available data to optimize the number of deployments they need to address their question of interest.

\section{Defining THE NoRm \\ (SAmple Sizes of a Few 10s up to 100)}

A better assessment of overall patterns of movement or behavior at the population scale may be possible after tens of individuals of the same species have been tagged. While specifying the sample size needed for these types of studies is challenging, simulation exercises can be useful as exploratory tools to understand how much data are needed. Using another simulation exercise, we illustrate how confidence in observed results can be improved by sample sizes increasing from $<10$ to a few tens of tags (Fig. 3B). As an example of a study question, we focused here on what is the clutch frequency of turtles, i.e., the frequency with which eggs are laid within and among seasons, which is a critical life-history trait for quantifying population trends of turtles. The number of nesting females in a population is typically determined by counting tracks on beaches associated with nesting and then dividing by a nominal mean frequency of clutches. A recent study that tracked 10 green turtles (Chelonia mydas) in Diego Garcia, Indian Ocean, showed that their mean clutch frequency was six (Esteban et al. 2017), and led to the understanding that the population at this locality was about one-half the size of that estimated from previous studies that patrolled beaches on foot to intercept females when they nested. Using the probabilities obtained in Esteban et al. (2017), we can simulate how the confidence limits on estimates of mean clutch frequency change with sample size. For 
A

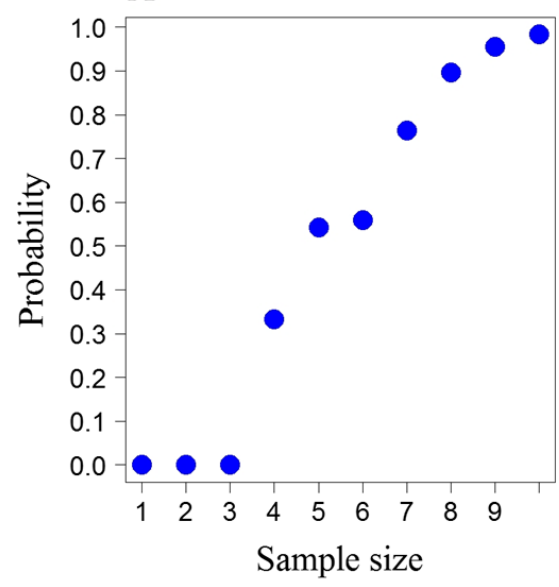

B

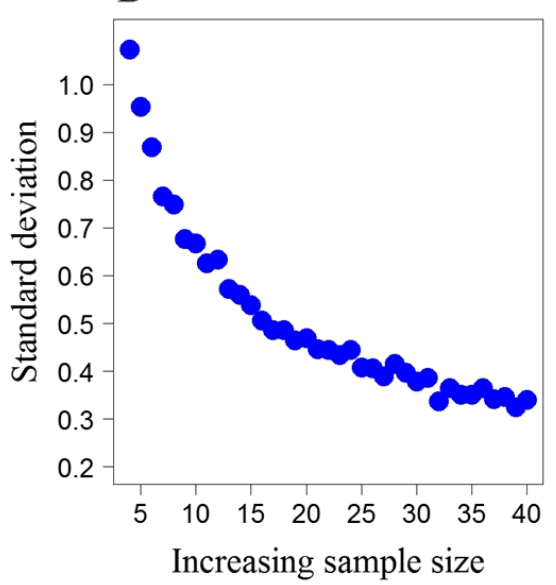

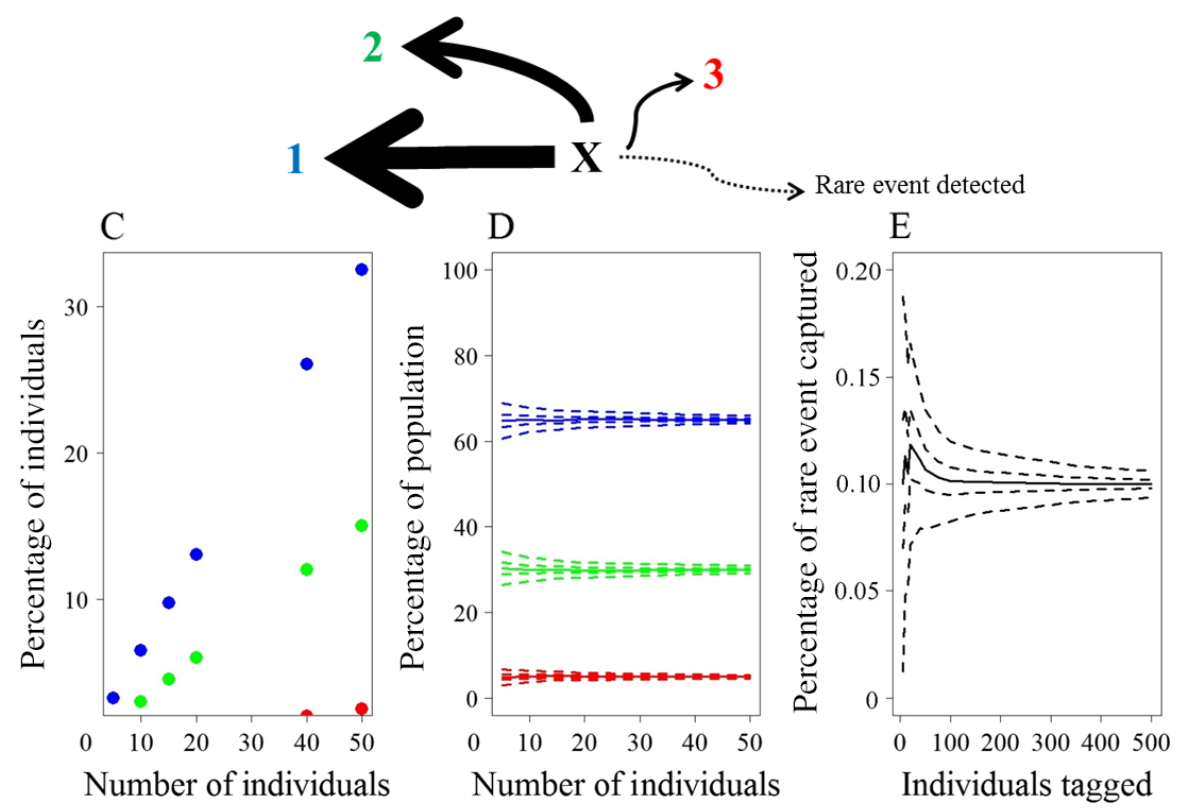

FIG. 3. Simulation examples to understand the effects of sample of size when addressing different key questions for the same guild (i.e., turtles). (A) Probability of finding differences in breeding periodicity of loggerhead turtles by simulating the number of males and females that would be recorded to return after $1 \mathrm{yr}$ and then testing if there is a significant difference $(P<0.05)$ in the numbers of returning males and females for increasing sample sizes up to 10 individuals. (B) Standard deviation of the estimate for mean clutch frequency for green turtles reflecting the variation that might be recorded for the mean estimate with different samples sizes. (C) Percentage of individuals perceived to travel to locations 1 (blue), 2 (green), and 3 (red) shown in the schematic representation displayed in the center of the figure as the number of tags deployed increases from 5 to 40 . The central scheme depicts movement dispersion and probabilities of detection of dispersion to different locations and detection of a rare event, with arrow width proportional to probability of dispersion from the tagging location X to each of the locations 1 (blue), 2 (green), and 3 (red) (0.65, 0.30 , and 0.05 ) for a population of 100 individuals. (D) Percentage of the population expected to travel to each of the locations 1,2 , and 3 depicted in the central scheme showing a decrease in the confidence intervals as the number of tags increases. (E) Representation of the confidence intervals for detection of possible rare events such as colonization of a new site.

each sample size (3-40), we ran 1,000 simulations and then determined the standard deviation (SD) of the estimate for mean clutch frequency, which reflects the variation in the estimate of mean clutch frequency that might be recorded with that sample size (Fig. 3B). When the sample size was three, the SD was $\sim 1.20$ (i.e., the $95 \%$ confidence limit on the estimate of mean clutch frequency that might have been derived was \pm 3 clutches), but when the sample size was increased to 30 , the SD reduced to 0.38 , and to 0.34 when the sample size was 40 individuals (i.e., $95 \%$ confidence limit $= \pm 0.11$ clutches). Examples of improvement on previous results through increased sample sizes are also found in published literature. For example, assessment of the diving behavior of 13 female northern elephant seals showed maximum dive durations of 106 min (Le Boeuf et al. 2000) and 
was confirmed as a good approximation in a later study with a sample of 211 females aimed at identifying drivers of their large-scale distribution and interannual variability in foraging and breeding success (Robinson et al. 2012). Despite the different focus of these two studies, the later data confirmed that the earlier study had a large enough sample size to provide a general understanding of the dive behavior of the species.

Commonly, tagging studies aim to quantify space use and identify important utilization areas (e.g., 50\% kernel densities). Such estimates are highly sensitive to sample size due to variability in movement among individuals, as shown by Gutowsky et al. (2015) with albatrosses. That study demonstrated that the sensitivity of grouplevel space-use estimates stabilizes with increasing sample size of albatrosses, in that the areas covered by space use estimates generated from data sets comprising different individuals roughly approached an asymptote in median area estimates around a mean sample size of 1721 individuals. However, the range of estimates remained large with the $95 \%$ and $50 \%$ contour area estimates varying by 7.2 and 1 million $\mathrm{km}^{2}$, respectively. For other seabirds, like European Shags (Phalacrocorax aristotelis) and Black-legged Kittiwakes (Rissa tridactyla), sample sizes of 39 and 83 have been used, respectively, to estimate space use (Soanes et al. 2013). Estimates of area utilization are also highly dependent on the animal's range and the context of habitat utilization. For example, a sample size of 30 was sufficient for calculating the area used by flatback turtles (Natator depressus) during the nesting season but not for calculating the typically larger area used post breeding (Thums et al. 2018b).

To demonstrate the effect of sample size on utilization area and kernel estimates for a range of species, we used a resampling approach to test whether an asymptotic relationship between sample size and monthly utilization area estimates was attained. We did this for probability contours of $50 \%$ and $25 \%$ (typically considered of relevance to marine spatial planning) using tracking data from six different species in the Pacific Ocean (results detailed in Fig. 4). Together, these studies demonstrate the power and limitations of a moderate number of tags to improve our understanding of animal movements. Another example showing how an increasing number of tracks can assist our understanding of animal movement was a study tracking $75 \log$ gerhead turtles across the Mediterranean finding that they exhibit disparate dispersal patterns. The study highlighted that extending protected areas to include 10 of the core sites used by loggerhead turtles would result in better protection for $64 \%$ of the population (Schofield et al. 2013).

To depict the effect of sample size on our understanding of dispersal of individuals from a population, we used a simulation of a hypothetical population of 100 individuals in location $\mathrm{X}$ where tagging took place, and then assumed equal probabilities of $0.65,0.30$, and 0.05 for individuals to go to location 1,2 , and 3 , respectively (Fig. 3C). Increasing the number of randomly tagged individuals from 5 to 50 , and repeating this procedure
10,000 times, showed that accurate detection of movements to location 3 was only possible at the higher number of tags $(n \sim 40)$. Moreover, precision around the percentage of the population travelling to each location increased with increasing numbers of tag deployments. In our example, $95 \%$ confidence intervals for the percentage of the population travelling to 1 narrowed from between $61.0-69.1 \%$ to between $64.1-66.0 \%$ as sample size increased from 1 to 40 tags, with similar reductions obtained for the other locations. As we have demonstrated, power-analysis needs some understanding of the system to allow the model to be parameterized and can be used to assess if there is further information likely to be obtained by tagging more individuals. However, it is important to highlight that simulation results only provide an idea of how many representative tracks are needed and do not consider the excess tags needed to account for potential problems with data acquisition, such as early tag failure or loss prior to exhaustion of battery, as mentioned earlier. So, interpretation of the results presented above is that little further detail would be gained after obtaining more than 40 representative tracks to answer a specific question about dispersal patterns. However, new and different questions may emerge to justify further tag deployments. Examples would include the need to assess inter-annual variability in movements or to address tagging sampling design to adjust not only for sample size but also sex ratio of animals tagged, size range, or range of capture and release sites.

As sample size increases, improved evaluation of the use of marine protected areas (MPAs) also becomes possible. Although the following studies provide only examples of detected patterns for the sample size used, what is crucial here is that having a large enough sample size across different seasons, sites or stages (e.g., breeding vs. non-breeding) allows detection of gradients across other variables of interest including environmental variables for habitat use detection. For example, acoustic tagging of 57 sharks showed that only one-half of the available protected space was used while sharks made excursions in and out of MPAs at consistent locations along the boundaries (Knip et al. 2012). Deployment of multiple tens of tags (simultaneous or staggered in time) can, therefore, provide insight into the scale of spatiotemporal movements to assist tailoring MPA design for improved effectiveness. Similarly, tens of tags can assist the assessment of movement variability driven by changes in environmental conditions. For example, behavioral changes by 32 fur seals were associated with strong El Niño conditions (Lea et al. 2006), movement of 40 bonnethead sharks (Sphyrna tiburo) changed in association with decreased salinity due to freshwater discharge (Ubeda et al. 2009), and foraging success of 50 Little penguins (Eudyptula minor) was shown to relate to boundary current anomalies in different years (Carroll et al. 2016). Detection of philopatry in highly migratory species has also been possible when using a sample size of tens of tags. Jorgensen et al. (2010) showed high philopatry in the migratory behavior of white sharks 

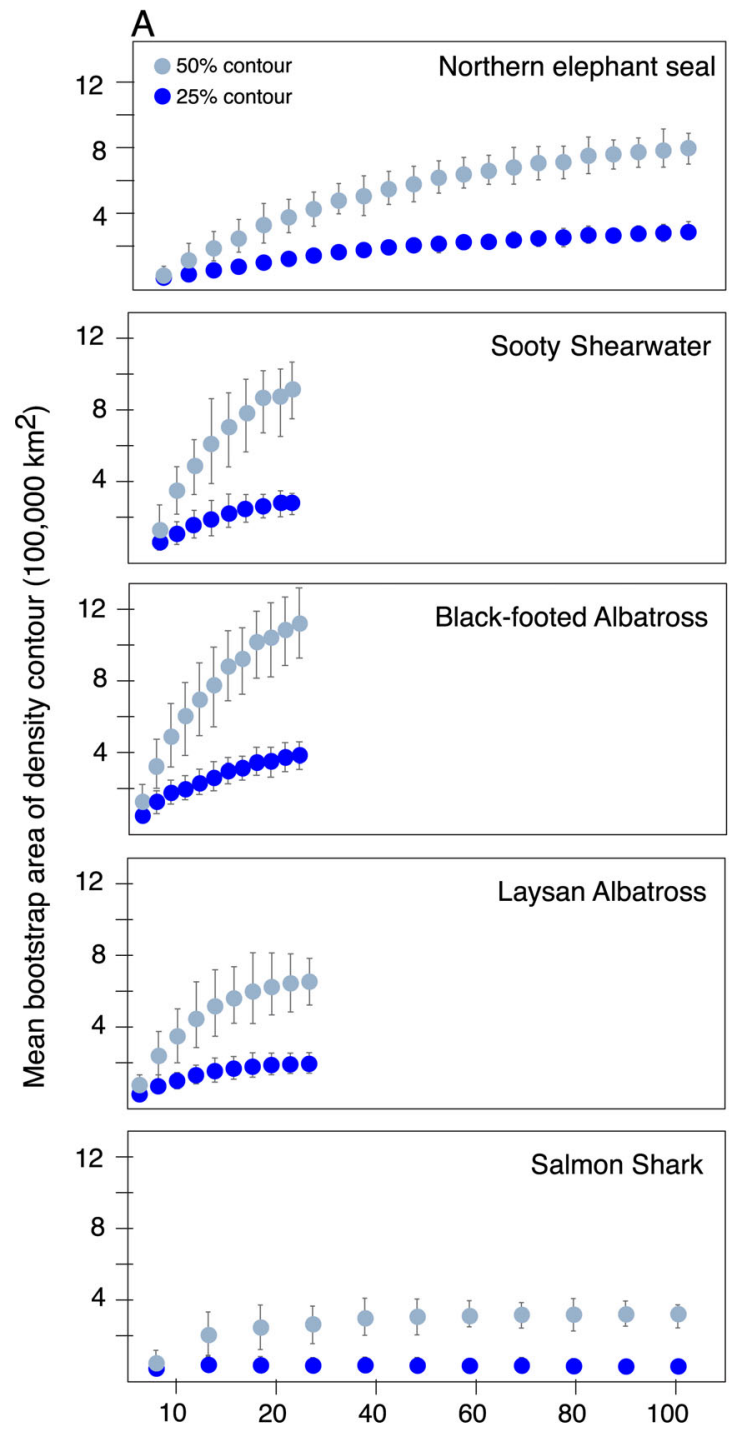

B
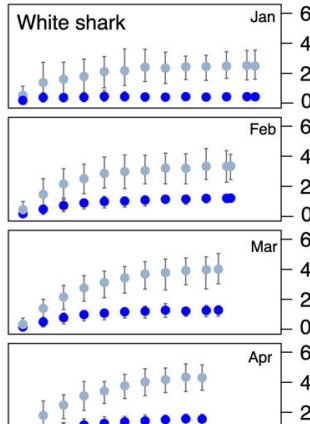

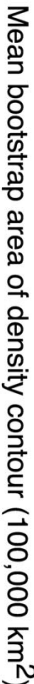

Resamples (number of individuals)

FIG. 4. Effects of sample size on estimates of utilization area at core probability contours $(50 \%$ and $25 \%)$ as function of sample size for six marine predator species. Bootstrapped estimates of area as a function of sample size (number of individuals tracked) of the $50 \%$ (light blue) and $25 \%$ (dark blue) contours of population utilization distributions calculated for electronically tracked marine animals. (A) Estimates for five migratory marine predators for the month of September pooled across years (2002-2009; available sample sizes varied across species). (B) Monthly estimates for white shark (pooled across years, 2000-2007, available sample sizes varied across months). Circles represent mean values and lines represent standard deviations. Adapted from Harrison (2012) using data from the Tagging of Pacific Predators project (Block et al. 2011). The evaluated data set consisted of 604 individual tracks and sample sizes varied across species (12-231 individuals) and across months (1-114 individuals). Plots show means and standard deviation of home range area, with mean estimates initially increasing as a function of the number of individuals tracked (the home range area of one individual is likely much smaller than the utilization distribution of 10 individuals). Once most of the variability in the population is captured, the estimate of space use of the population stabilizes resulting in an asymptote in the plot. Estimates of home range size approached an asymptote for Northern elephant seals and salmon sharks (species with data sets of 57-108 individuals) at sample sizes of 20-40 individuals in most months at all contour levels. In contrast, for estimates calculated from samples sizes between 10 and 30 individuals for (A) Black-footed Albatross, Laysan Albatross, sooty Shearwater, and Pacific bluefin tuna that were recorded to undertake their trans-Pacific migration, and (B) white sharks from June through September), the sample size was insufficient to observe an asymptote in estimates of utilization area (especially at the largest probability contours that would capture rare events). There were also large confidence intervals around the area estimates for these species' data sets, implying that larger data sets were needed to increase the precision and accuracy of the estimates. 
based on the results from 68 satellite-linked tags and revealed a predictive migratory cycle within the same network of coastal hotspots for a genetically distinct population. The larger sample sizes used in these examples enabled researchers to claim that their results were representative of the wider population of these species.

Although an individual study might include only a few tags, sample sizes in the 10s (and greater) can be obtained by pooling data across studies, allowing researchers to pose new questions and search for general patterns. For example, the compilation of eight studies with low individual sample sizes (1-13 summing to 50 tags) across the Mediterranean Sea and the Pacific, Atlantic, and Indian Oceans confirmed previous concerns of high sea turtle mortalities by fisheries (Hays et al. 2003). The same applies to multispecies studies, where even low sample sizes for individuals of different species pooled together allow some level of interspecies comparisons. For example, informed comparison of vertical movement patterns and their statistical properties across taxa were obtained with data from 31 individuals from seven species (Sims et al. 2008). While the sample size of the later study was relatively small, the high resolution of the diving data contained in the tracks, which included over one million data points, allow for a comparative multispecies analysis.

\section{Defining Population Parameters (SAmple Sizes 100)}

With the implicit assumption that each tag results in an appropriate amount of data (e.g., number of locations and enough resolution), improved accuracy in our understanding of patterns (e.g., space use) can be obtained using a larger number of tagged animals (see examples of northern elephant seals and salmon sharks, Lamna ditropis, in Fig. 4A). As sample sizes approach 100, it becomes possible to assess movement behavior between populations of the same species and across large areas. For example, 101 tracks of leatherback turtles were used to define areas of high susceptibility to by-catch across the Atlantic Ocean (Fossette et al. 2014). In this example, a large sample size was necessary to encompass a range of different nesting populations, all of which foraged within the Atlantic. Likewise, Breed et al. (2006) investigated segregation of seasonal foraging habitats of grey seals from 95 tagged individuals. In cases where sex or age leads to segregated behavior, the number of tags needed to detect specific patterns of movement will necessarily be inflated to identify potential behavioral mechanisms, and more so if a comparison across populations is to be completed. As the spatial scale under consideration increases, so too does the minimum number of tags, until even sample sizes of 100 may be insufficient. For example, when Sequeira et al. (2013) compiled all publicly available tracking data for whale sharks, they found that the existing $\sim 100$ tracks (average $90 \mathrm{~d}$ deployment with a range from hours to $>3 \mathrm{yr}$ ) were insufficient to reveal global migration patterns.

Assessment of animal health and increasing anthropogenic impacts on movement is also highly relevant and urgently sought for many species. For example, data from 136 West Indian manatees were used to assess rehabilitation success following release (Adimey et al. 2016). However, the large sample sizes needed for assessing effects at the species level are not commonly available (but see Fossette et al. 2014), and pooling data across species of the same guild might provide the means to obtain relevant information. This was the case for a data set of 113 oceanic sharks examined to detect spatial overlap with commercial fisheries. This data set comprised tracks from six species (average of 17 tags per species) and led to the revelation that shark hotspots in the North Atlantic Ocean may be at risk from overfishing (Queiroz et al. 2016). Similarly, passive acoustic tracking of 116 reef sharks of five species (average of 17 tags per species) together with 25 hawksbill turtles (Eretmochelys imbricata) determined the long-term, fine-scale space use inside and outside a marine protected area (MPA) for each species. This study also revealed that a modest increase in MPA size could lead to a $34 \%$ increase in spatial coverage of these predator's movements (Lea et al. 2016).

\section{Moving Toward Big Data Analysis (Very Large Sample Sizes; 〉100)}

Common areas of space use at large spatial scales can be revealed using a large number of tagged individuals $(\gg 100)$. For example, Wakefield et al. (2013) used tracking data of 184 Northern Gannets from different breeding areas to assess the levels of foraging area overlap around the British Isles. A much larger tracking data set of 287 individual elephant seals led to an improved understanding of how these seals utilize the circumpolar habitat in the Southern Ocean (Hindell et al. 2016). Large data sets also allow application of big data approaches, which are scalable to very large numbers of tracks (e.g., as used in human mobility studies). A recent example of the application of such approaches to tracking data of 272 southern elephant seals showed that, despite idiosyncrasies in movement, a clear signature of directed movement emerged, highlighting the presence of intrinsic drivers of movement such as memory (Rodriguez et al. 2017). In addition, samples size in the hundreds can reveal correlated or coordinated movement patterns among individuals. An example is the coherent movement patterns suggested by the sonification of movement (i.e., the generation of sound based on the movement patterns in the tracking data) of over 300 northern elephant seals tagged over $\sim 10 \mathrm{yr}$ in the Northeast Pacific Ocean (Duarte et al. 2018). These studies show that the use of techniques that can deal with big data (Leek et al. 2017) might bring new insights to movement ecology.

Very large sample sizes of single species can also be useful to increase the probability of defining events not commonly detected using tags, such as colonization of a new site or mortality (Hays et al. 2003). To illustrate this point, we extended the simulation exercise presented above to consider how many tags would be needed to 
detect a rare event with a probability of 0.001 and showed that hundreds of tags would be required (Fig. 3E).

For multiple species, the quantity of information returned climbs dramatically as sample size increases to many hundreds, particularly for assessing movement patterns in response to resource fields within the same geographical extent. For example, in East Antarctica, a compilation of 268 satellite tracks for six top predators including penguins, albatrosses, and seals revealed areas of particular ecological significance for these multiple species (Raymond et al. 2015). Maxwell et al. (2013) used tracks from 685 individuals of eight species in the North Pacific, to show high variability in the distribution of cumulative impacts across species and highlight that effective spatial management will need to account for trade-offs among stressors. These individuals had been tagged as part of the Tagging of Pacific Predators (TOPP) project, a much larger collaborative effort under the Census of Marine Life field program, which led to the deployment of an unprecedented number of tags $(4,300)$. Of these, 1,791 tracks were used in a single study to assess space use by multiple predatory species in the Pacific Ocean highlighting hotspots, migration pathways, and niche partitioning among species (Block et al. 2011), and was used to predict how climate change will affect the available habitat for different species (Hazen et al. 2013). Another subset of 1,648 tracks representing 14 species was also used to show annual patterns of movements through the high seas and across geopolitical boundaries in the Pacific Ocean (Harrison et al. 2018). Most recently, the coastal movements of 2,181 individuals from 92 species including fish, sharks, turtles, and marine mammals were used to identify four distinct functional movement classes in the coastal waters of Australia, with these classes emerging only through aggregating data across the entire data set (Brodie et al. 2018). Finally, the Marine Megafauna Movement Analytical Program (MMMAP) used $>2,500$ individual tracks across 50 species of marine vertebrates including whales, sharks, seals, seabirds, polar bears, sirenians, and turtles, to show that, unlike terrestrial animals, movement patterns in marine animals are strongly conserved across species regardless of evolutionary history, with movements being more complex in the coastal than in the open ocean (Sequeira et al. 2018). As these large aggregated data sets increase further in size, their temporal and spatial coverage may become sufficient to retrospectively detect signals of climate change or other perturbations in the movement patterns of species (Weimerskirch et al. 2012).

In the last decade, many tens of thousands of tags have been deployed on animals and, if shared, the resulting data sets will allow for powerful analysis at large spatiotemporal scales (Thums et al. 2018a). Such data sets can assist in answering topical questions (Hays et al. 2016), refine conservation benefits (Allen and Singh 2016), and facilitate the use of big data approaches to enhance our understanding of animal movements (Meekan et al. 2017, Rodriguez et al. 2017). The advantages of data sharing for researchers are clear (Nguyen et al. 2017), and well-recognized in some fields of scientific inquiry such as molecular ecology and physical oceanography. Encouragingly, some tracking programs already have some type of open data policy, and a large range of online repositories are now available (Campbell et al. 2016), including Zoatrack (Dwyer et al. 2015), Movebank, the Integrated Marine Observing System (IMOS), and the Ocean Tracking Network (OTN). The increasing use of telemetry technology also supports unprecedented opportunities for collaboration among researchers studying different species.

By combining satellite tracking with acoustic detection and making relatively minor compromises on equipment sampling parameters (i.e., scanning range of tag frequencies and using collaborative acoustic monitoring arrays), there is potential for researchers to expand the spatial and temporal range of tracking efforts and collect data for multiple species simultaneously (Lidgard et al. 2014, Aven et al. 2015). The big, but heterogeneous data acquired by pooling data sets from a variety of sources will present a challenge for analysis, data visualization and storage. Ways to overcome such challenges have already been addressed in other disciplines. For example, studies of human mobility interrogate massive and rapidly growing databases of geolocations available from smart phones and internet records, which describe the movements of humans (Gonzalez et al. 2008). Although such studies focus on a single species (humans; Homo sapiens), they have shown the power of data encompassing tens of thousands of individuals to address questions associated with collective responses and with processes occurring at the population level. Great examples include the study of epidemics, transmission of culture or mood (Mocanu et al. 2013), or the development of models describing mobility patterns (e.g., radiation model; Simini et al. 2012).

\section{ConCLusion}

The answer to "how many animals should be tracked?" is intrinsically dependent on the species of interest, on the tagging methods used, and, primarily, on the question that needs to be addressed, including spatial and temporal coverage (see examples in Table 1). We point out that tracking studies usually develop in stages, including (1) an initial phase of "innovation and discovery" that commonly involves small sample sizes $(N \leq 10)$, through to (2) a stage of "confirmation and consolidation" of results with intermediate sample sizes $(10<N \leq 100)$, and, last, to (3) more synthetic, overarching, and inter-disciplinary studies involving larger sample sizes $(N \gg 100)$. At each stage, the impact of the sample size on the key conclusions can be assessed (e.g., the proportion of individuals travelling to different sites) and the outcomes of this assessment can be used to objectively plan how the sample size needs to be increased to answer different questions with the required level of confidence. As sample size 

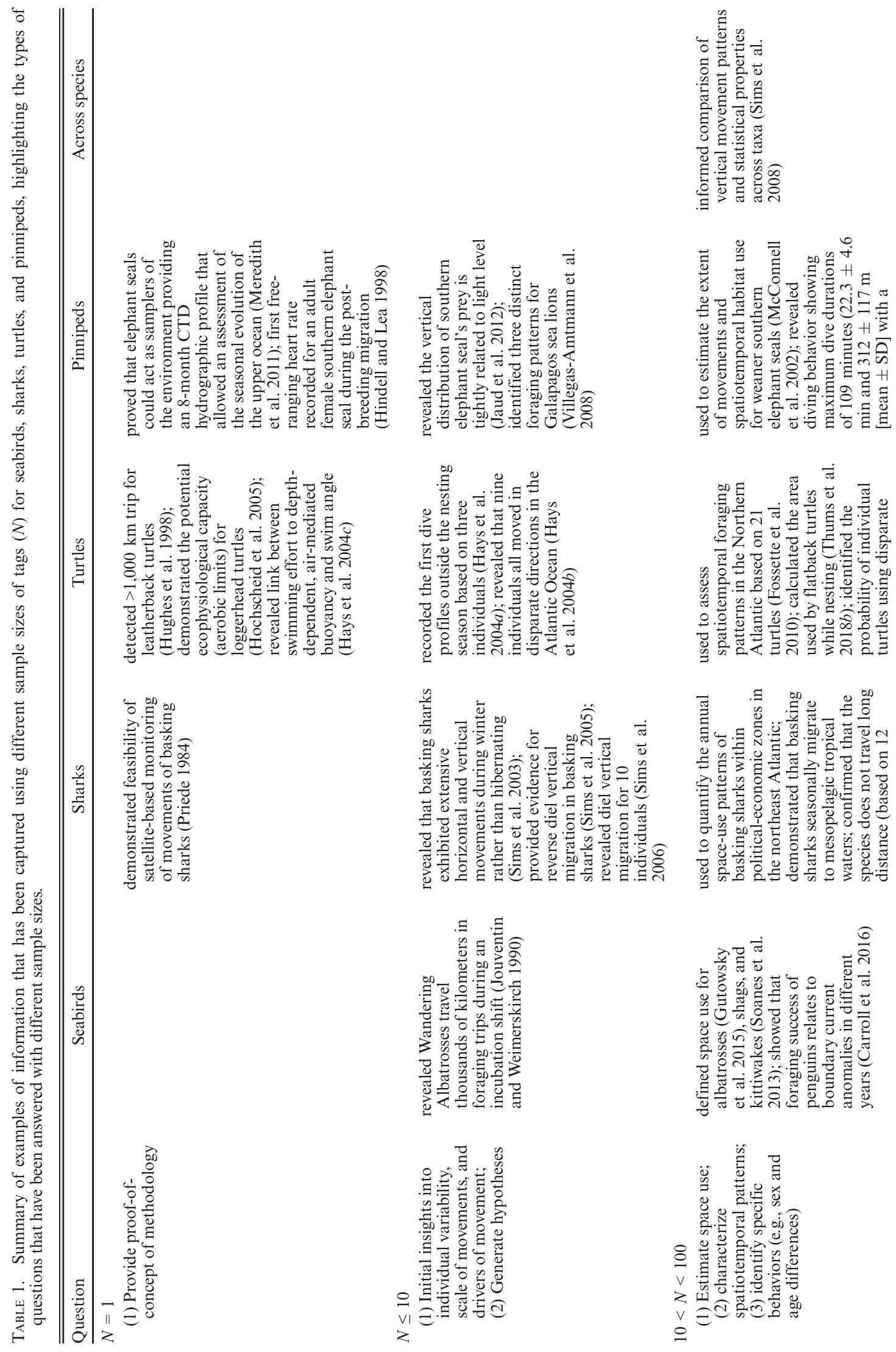


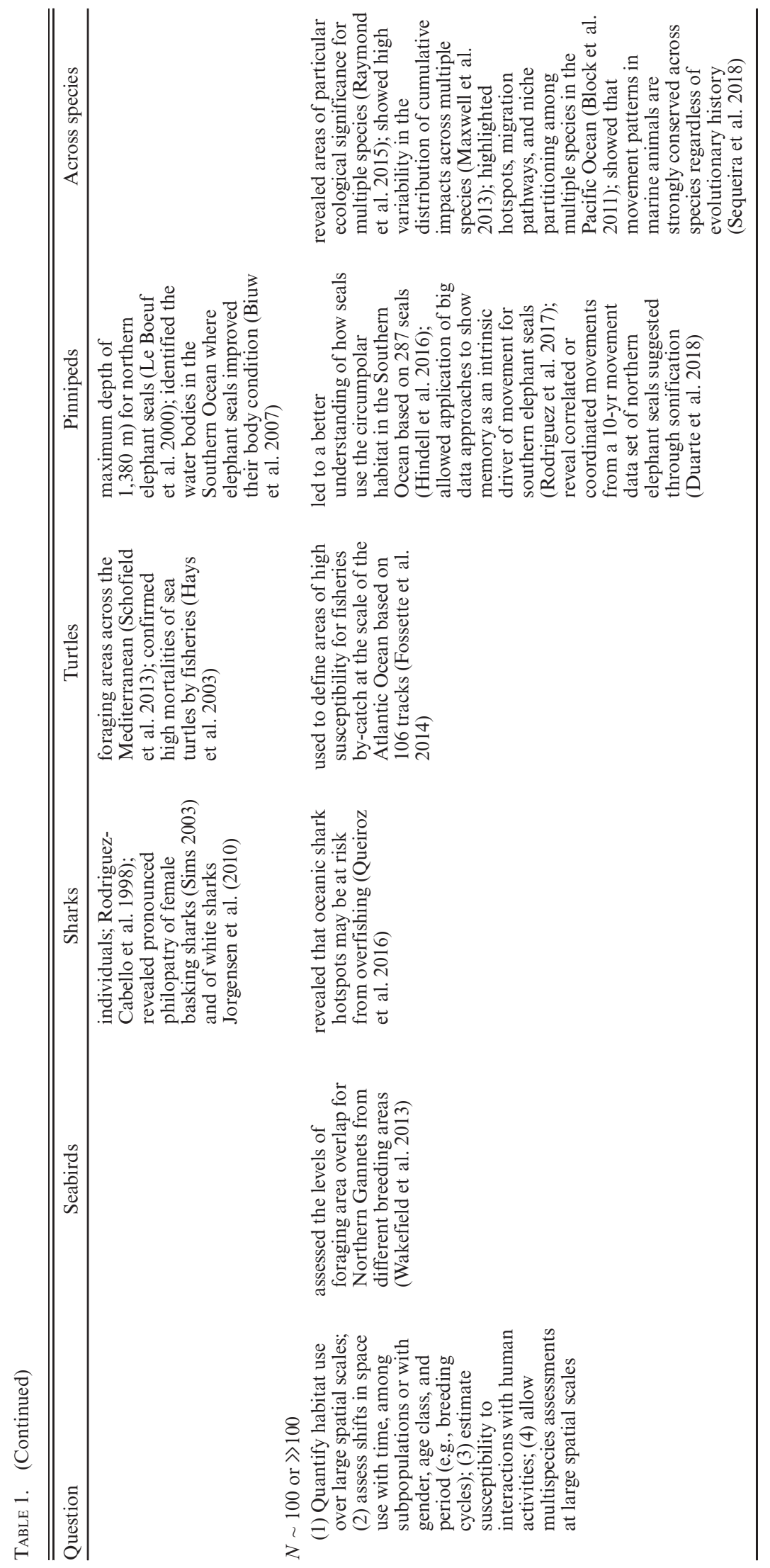


increases, both in relation to the number of individuals tracked and the length of individual tracks, there is improved ability to resolve a range of questions associated with movement, such as home-range estimates, migration patterns including identification of high-use corridors, migration distance and variability in destinations, and foraging search patterns. How large a sample size is needed to resolve these various movement components to a certain level of confidence will depend on the extent of individual variability and on the behavior of the species being tracked.

We caution that the same given number of tags can also lead to very different data depending on when the tags are deployed and the duration of the tag deployment. For example, for pinnipeds, tagging the individuals close to molting may result in a track of very short duration with the tag coming off before its battery is exhausted, while post-molt deployments will likely result in 8-9 months of tracking data (Treasure et al. 2017). For species that display different seasonal movement patterns, such as sirenians, differences in the data obtained with the same sample sizes can vary as much as detection of little movement in the peaks of summer or winter, to hundreds of kilometers of movement being captured in spring and fall (Aven et al. 2016). In the latter example, if a tag continues to function for 9-10 months, both high-resolution local data and wider regional habitat use can be obtained. In such cases, the timing and duration of a small number of tags may yield more or better information than larger sample sizes deployed at the wrong time. Moreover, as variability increases, so too will the sample size needed to resolve research questions. Similarly, variability has implications in studies pooling data sets across species and aiming to make inferences on comparisons across groups. In such cases, the number of individuals representing each specific group will affect the high-level inferences that can be made based on the pooled data sets. Comparing changes in space use over time is only as powerful as the smallest within-year group size; however, pooled data sets are generally useful to draw conclusions across groups.

We suggest that the planning of a tracking study should include a thorough search of the published literature where similar questions have been addressed (even if for other species). For example, studies provided in Table 1 show the types of questions that have been asked for species of different guilds with increasing sample size and can be used as guide for minimum numbers required by future studies. If prior information is available for the specific study species, then the use of simulation exercises similar to those presented in Figs. 3 and 4 (refer to DataS1: Sequeira et al_Simulation Code.R) can be informative. Also, when estimating utilization areas and kernel densities, a full evaluation of sensitivity to sample size should be carried out and results should be reported with the confidence estimates (Fig. 4).

It is often not possible to do a priori assessments of the importance of sample size as the various tracking outcomes are not known. In such cases, we suggest that the question to be addressed is explicitly defined so it becomes clear in which phase of research the question falls, i.e., "innovation and discovery," "confirmation or consolidation," or "synthetic, overarching, inter-disciplinary approach." Depending on the phase, the relative sample size (small, intermediate, or large) becomes easier to estimate. Once this target sample size has been identified, it then becomes useful to consult Table 1 to have an idea of the types of questions that have been addressed with specific sample sizes for different taxa. Generally, within each phase, the largest logistically feasible sample size should be employed, within ethical and logistical constraints. This is because larger sample sizes will provide greater confidence in species- or population-level inferences. However, sample sizes will necessarily be lower for rare or cryptic species, small or critically endangered populations, and when tagging may be too disruptive. The number of individuals tagged within populations, the amount and resolution of data, as well as, their accuracy also impact the types of questions that can be addressed. Therefore, in addition to the practical limitations in sample size in such situations, there will also be financial and research scope limitations.

Recent advances made in the field of telemetry and bio-logging have led to an exponential increase in satellite telemetry studies (Thums et al. 2018a), with very large sample size ( $\gg 1,000$ tracks) recently starting to appear in the literature (Block et al. 2011, Brodie et al. 2018, Sequeira et al. 2018). In spite of that, a sample size of one with sufficient track length can still lead to scientific insights. This is particularly relevant for species that have never been tracked before, when previous deployments have not been successful, or when testing new sensors (Lennox et al. 2017). In such situations, and where the current knowledge of a species' movement is still in its infancy, any new insights from small sample sizes have the potential to significantly advance knowledge. In contrast, for species where tracking is well established (e.g., some seals or turtles and seabirds), the questions relating to population densities, biologically important areas, population structure, or social networking will require tracks of many individuals, or can be addressed by retrospective analysis after combining existing data across studies and including multiple researchers. Clearly, there are many challenges to statistically estimate an appropriate sample size for telemetry studies across the many and varied contexts. Our review highlights these challenges and provides recommendations based on examples and data simulations to assist in decision making.

\section{ACKNOWLEDGMENTS}

G. C. Hays conceived the study and a first draft was compiled by A. M. M. Sequeira, G. C. Hays, M. Heupel, M.-A. Lea, and V. M. Eguíluz at a workshop organized by M. Thums, A. M. M. Sequeira, C. M. Duarte, M. G. Meekan, and V. M. Eguíluz. A. M. M. Sequeira and G. C. Hays led the writing of the manuscript. A. M. M. Sequeira, G. C. Hays, A.-L. Harrison, and H. J. 
Calich prepared the figures. All authors contributed to the manuscript and commented on drafts. A. M. M. Sequeira was supported by an ARC Grant (DE170100841), and the Australian Institute of Marine Science, G.C. Hays by the Bertarelli Foundation as part of the Bertarelli Programme in Marine Science, and H. J. Calich by an Australian Government RTP scholarship at UWA. Workshop funding was granted to M. Thums, A. M. M. Sequeira, and C. M. Duarte by the UWA Oceans Institute, the Australian Institute of Marine Science, and the Office of Sponsored Research at King Abdullah University of Science and Technology (KAUST). We thank F. Bailleul, S. Goldsworthy, M. Hindell, and all other workshop attendees for initial discussions.

\section{Literature Cited}

Adimey, N. M., M. Ross, M. Hall, J. P. Reid, M. E. Barlas, L. W. K. Diagne, and R. K. Bonde. 2016. Twenty-six years of post-release monitoring of Florida Manatees (Trichechus manatus latirostris): evaluation of a cooperative rehabilitation program. Aquatic Mammals 42:376-391.

Allen, A. M., and N. J. Singh. 2016. Linking movement ecology with wildlife management and conservation. Frontiers in Ecology and Evolution 3:13.

Aven, A. M., R. H. Carmichael, M. J. Ajemian, and S. P. Powers. 2015. Addition of passive acoustic telemetry mitigates lost data from satellite-tracked manatees. Marine and Freshwater Research 66:371-374.

Aven, A., R. H. Carmichael, E. E. Hieb, and M. Ross. 2016. West Indian manatee movements reveal novel occupancy and distribution patterns in the northern Gulf of Mexico. PeerJ Preprints 4:e2072v1. https://doi.org/10.7287/peerj.preprints. 2072v1.

Biuw, M., et al. 2007. Variations in behavior and condition of a Southern Ocean top predator in relation to in situ oceanographic conditions. Proceedings of the National Academy of Sciences USA 104:13705-13710.

Block, B. A., et al. 2011. Tracking apex marine predator movements in a dynamic ocean. Nature 475:86-90.

Bonfil, R., M. Meÿer, M. C. Scholl, R. Johnson, S. O'Brien, H. Oosthuizen, S. Swanson, D. Kotze, and M. Paterson. 2005. Transoceanic migration, spatial dynamics, and population linkages of white sharks. Science 310:100-103.

Breed, G. A., W. D. Bowen, J. I. McMillan, and M. L. Leonard. 2006. Sexual segregation of seasonal foraging habitats in a non-migratory marine mammal. Proceedings of the Royal Society B 273:2319-2326.

Brodie, S., et al. 2018. Continental-scale animal tracking reveals functional movement classes across marine taxa. Scientific Reports 8:3717. https://doi.org/10.1038/s41598-018-21988-5.

Campbell, H. A., F. Urbano, S. Davidson, H. Dettki, and F. Cagnacci. 2016. A plea for standards in reporting data collected by animal-borne electronic devices. Animal Biotelemetry 4:1. https://doi.org/10.1186/s40317-015-0096-x.

Carey, F. G., J. W. Kanwisher, O. Brazier, G. Gabrielson, J. G. Casey, and H. L. Pratt. 1982. Temperature and activities of a White Shark, Carcharodon-Carcharias. Copeia 2:254-260.

Carroll, G., J. D. Everett, R. Harcourt, D. Slip, and I. Jonsen. 2016. High sea surface temperatures driven by a strengthening current reduce foraging success by penguins. Scientific Reports 6:22236. https://doi.org/10.1038/srep22236.

Deutsch, C. J., J. P. Reid, R. K. Bonde, D. E. Easton, H. I. Kochman, and T. J. O'Shea. 2003. Seasonal movements, migratory behavior, and site fidelity of West Indian manatees along the Atlantic Coast of the United States. Wildlife Monographs 151:1-77.

Duarte, C. M., P. Riker, M. Srinivasan, P. W. Robinson, J. P. Gallo-Reynoso, and D. P. Costa. 2018. Sonification of
Northern elephant seal suggests concerted movement across the NE Pacific Ocean. Frontiers in Marine Science. https://d oi.org/10.3389/fmars.2018.00128.

Durban, J. W., and R. L. Pitman. 2012. Antarctic killer whales make rapid, round-trip movements to subtropical waters: evidence for physiological maintenance migrations? Biology Letters 8:274-277.

Dwyer, R. G., C. Brooking, W. Brimblecombe, H. A. Campbell, J. Hunter, M. Watts, and C. E. Franklin. 2015. An open webbased system for the analysis and sharing and analysis of animal tracking data. Animal Biotelemetry $3: 11$. https://doi.org/ 10.1186/s40317-014-0021-8.

Esteban, N., J. Mortimer, and G. Hays. 2017. How numbers of nesting sea turtles can be overestimated by nearly a factor of two. Proceedings of the Royal Society B 284:20162581. http:// doi.org/10.1098/rspb.2016.2581.

Evans, K., M. A. Lea, and T. A. Patterson. 2013. Recent advances in bio-logging science: Technologies and methods for understanding animal behaviour and physiology and their environments Introduction. Deep-Sea Research Part II-Topical Studies in Oceanography 88-89:1-6.

Fossette, S., V. J. Hobson, C. Girard, B. Calmettes, P. Gaspar, J.-Y. Georges, and G. C. Hays. 2010. Spatio-temporal foraging patterns of a giant zooplanktivore, the leatherback turtle. Journal of Marine Systems 81:225-234.

Fossette, S., et al. 2014. Pan-Atlantic analysis of the overlap of a highly migratory species, the leatherback turtle, with pelagic longline fisheries. Proceedings of the Royal Society B 281: 20133065. http://doi.org/10.1098/rspb.2013.3065.

Gonzalez, M. C., C. A. Hidalgo, and A.-L. Barabási. 2008. Understanding individual human mobility patterns. Nature 453:779-782.

Green, R. H. 1989. Power analysis and practical strategies for environmental monitoring. Environmental Research 50:195-205.

Gutowsky, S. E., M. L. Leonard, M. G. Conners, S. A. Shaffer, and I. D. Jonsen. 2015. Individual-level variation and higherlevel interpretations of space use in wide-ranging species: an albatross case study of sampling effects. Frontiers in Marine Science 2:17.

Harcourt, R. G., E. Turner, A. Hall, J. R. Waas, and M. Hindell. 2010. Effects of capture stress on free-ranging, reproductively active male Weddell seals. Journal of Comparative Physiology A-Neuroethology Sensory Neural and Behavioral Physiology 196:147-154.

Harrison, A. L. 2012. A synthesis of marine predator migrations, distribution, species overlap, and use of Pacific Ocean Exclusive Economic Zones. Dissertation. University of California, Santa Cruz, Santa Cruz, California, USA. https://esc holarship.org/uc/item/1vh7h6jx.

Harrison, A. L., et al. 2018. The political biogeography of migratory marine predators. Nature Ecology \& Evolution 2:1571-1578

Hays, G., et al. 2019. Translating marine animal tracking data into conservation policy and management. Trends in Ecology and Evolution 15. https://doi.org/10.1016/j.tree.2019.01.009.

Hays, G. C., A. C. Broderick, B. J. Godley, P. Luschi, and W. J. Nichois. 2003. Satellite telemetry suggests high levels of fishing-induced mortality in marine turtles. Marine Ecology Progress Series 262:305-309.

Hays, G. C., J. D. R. Houghton, C. Isaacs, R. S. King, C. Lloyd, and P. Lovell. 2004a. First records of oceanic dive profiles for leatherback turtles, Dermochelys coriacea, indicate behavioural plasticity associated with long-distance migration. Animal Behaviour 67:733-743

Hays, G. C., J. D. R. Houghton, and A. E. Myers. $2004 b$. Endangered species-Pan-Atlantic leatherback turtle movements. Nature 429:522-522. 
Hays, G. C., J. D. Metcalfe, A. W. Walne, and R. P. Wilson $2004 c$. First records of flipper beat frequency during sea turtle diving. Journal of Experimental Marine Biology and Ecology 303:243-260.

Hays, G. C., A. D. Mazaris, and G. Schofield. 2014a. Different male vs. female breeding periodicity helps mitigate offspring sex ratio skews in sea turtles. Frontiers in Marine Science 1:9.

Hays, G. C., J. A. Mortimer, D. Ierodiaconou, and N. Esteban. 2014b. Use of Long-distance migration patterns of an endangered species to inform conservation planning for the World's largest marine protected area. Conservation Biology 28:16361644.

Hays, G. C., et al. 2016. Key questions in marine Megafauna movement ecology. Trends in Ecology \& Evolution 31:463-475.

Hazen, E. L., et al. 2013. Predicted habitat shifts of Pacific top predators in a changing climate. Nature Climate Change 3:234-238.

Hebblewhite, M., and D. T. Haydon. 2010. Distinguishing technology from biology: a critical review of the use of GPS telemetry data in ecology. Philosophical Transactions of the Royal Society B 365:2303-2312.

Heupel, M. R., C. A. Simpfendorfer, and R. Fitzpatrick. 2010 Large-scale movement and reef fidelity of grey reef sharks. PLOS ONE 5:e9650.

Hindell, M. A., and M. A. Lea. 1998. Heart rate, swimming speed, and estimated oxygen consumption of a free-ranging southern elephant seal. Physiological Zoology 71:74-84.

Hindell, M. A., et al. 2016. Circumpolar habitat use in the southern elephant seal: implications for foraging success and population trajectories. Ecosphere 7:e01213.

Hochscheid, S., F. Bentivegna, and G. C. Hays. 2005. First, records of dive durations for a hibernating sea turtle. Biology Letters 1:82-86.

Hughes, G. R., P. Luschi, R. Mencacci, and F. Papi. 1998. The $7000-\mathrm{km}$ oceanic journey of a leatherback turtle tracked by satellite. Journal of Experimental Marine Biology and Ecology 229:209-217.

Hussey, N. E., et al. 2015. Aquatic animal telemetry: a panoramic window into the underwater world. Science 348:1221-1231.

Jaud, T., A. C. Dragon, J. V. Garcia, and C. Guinet. 2012. Relationship between chlorophyll a concentration, light attenuation and diving depth of the southern elephant seal Mirounga leonina. PLoS ONE 7:e47444. https://doi.org/10.1371/journal. pone. 0047444

Johnson, P. C. D., S. J. E. Barry, H. M. Ferguson, and P. Muller. 2015. Power analysis for generalized linear mixed models in ecology and evolution. Methods in Ecology and Evolution 6:133-142.

Jorgensen, S. J., C. A. Reeb, T. K. Chapple, S. Anderson, C. Perle, S. R. Van Sommeran, C. Fritz-Cope, A. C. Brown, A. P. Klimley, and B. A. Block. 2010. Philopatry and migration of Pacific white sharks. Proceedings of the Royal Society B 277:679-688.

Jouventin, P., and H. Weimerskirch. 1990. Satellite tracking of wandering albatrosses. Nature 343:746-748.

Kays, R., M. C. Crofoot, W. Jetz, and M. Wikelski. 2015. Terrestrial animal tracking as an eye on life and planet. Science 348:1222-1231.

Knip, D. M., M. R. Heupel, and C. A. Simpfendorfer. 2012. Evaluating marine protected areas for the conservation of tropical coastal sharks. Biological Conservation 148:200-209.

Le Boeuf, B. J., D. E. Crocker, D. P. Costa, S. B. Blackwell, P. M. Webb, and D. S. Houser. 2000. Foraging ecology of northern elephant seals. Ecological Monographs 70:353-382.

Lea, M. A., and L. Dubroca. 2003. Fine-scale linkages between the diving behaviour of Antarctic fur seals and oceanographic features in the southern Indian Ocean. ICES Journal of Marine Science 60:990-1002.
Lea, M. A., C. Guinet, Y. Cherel, G. Duhamel, L. Dubroca, P. Pruvost, and M. Hindell. 2006. Impacts of climatic anomalies on provisioning strategies of a Southern Ocean predator. Marine Ecology Progress Series 310:77-94.

Lea, J. S. E., N. E. Humphries, R. G. von Brandis, C. R. Clarke, and D. W. Sims. 2016. Acoustic telemetry and network analysis reveal the space use of multiple reef predators and enhance marine protected area design. 283:20160717. https://doi.org/ 10.1098/rspb.2016.0717.

Leek, J., B. B. McShane, A. Gelman, D. Colquhoun, M. B. Nuijten, and S. N. Goodman. 2017. Five ways to fix statistics. Nature 551:557-559.

Lennox, R. J., et al. 2017. Envisioning the future of aquatic animal tracking: technology, science, and application. BioScience 67:884-896.

Lidgard, D. C., W. D. Bowen, I. D. Jonsen, and S. J. Iverson. 2014. Predator-borne acoustic transceivers and GPS tracking reveal spatial and temporal patterns of encounters with acoustically-tagged fish in the open ocean. Marine Ecology Progress Series 501:157-168.

Mate, B. R., V. Y. Ilyashenko, A. L. Bradford, V. V. Vertyankin, G. A. Tsidulko, V. V. Rozhnov, and L. M. Irvine. 2015. Critically endangered western gray whales migrate to the eastern North Pacific. Biology Letters 11:20150071. https://doi.org/ 10.1098/rsbl.2015.0071.

Maxwell, S. M., et al. 2013. Cumulative human impacts on marine predators. Nature Communications 4:2688. https:// doi.org/10.1038/ncomms3688.

McConnell, B., M. Fedak, H. R. Burton, G. H. Engelhard, and P. J. H. Reijnders. 2002. Movements and foraging areas of naive, recently weaned southern elephant seal pups. Journal of Animal Ecology 71:65-78.

McMahon, C., and G. C. Hays. 2006. Thermal niche, largescale movements and implications of climate change for a critically endangered marine vertebrate. Global Change Biology 12:1330-1338.

Meekan, M. G., L. A. Fuiman, R. Davis, Y. Berger, and M. Thums. 2015. Swimming strategy and body plan of the world's largest fish: implications for foraging efficiency and thermoregulation. Frontiers in Marine. Science 2:64. https:// doi.org/10.3389/fmars.2015.00064.

Meekan, M. G., C. M. Duarte, J. Fernandez-Gracia, M. Thums, A. M. Sequeira, R. Harcourt, and V. M. Eguiluz. 2017. The ecology of human mobility. Trends in Ecology \& Evolution 32:198-210

Meredith, M. P., K. W. Nicholls, I. A. Renfrew, L. Boehme, M. Biuw, and M. Fedak. 2011. Seasonal evolution of the upperocean adjacent to the South Orkney Islands, Southern Ocean: results from a "lazy biological mooring." Deep-Sea Research Part II-Topical Studies in Oceanography 58:1569-1579.

Mocanu, D., A. Baronchelli, N. Perra, B. Goncalves, Q. Zhang, and A. Vespignani. 2013. The twitter of Babel: mapping world languages through microblogging platforms. PLOS ONE 8: e61981. https://doi.org/10.1371/journal.pone.0061981.

Nguyen, V., J. L. Brooks, N. Young, R. J. Lennox, N. Haddaway, F. Whoriskey, R. Harcourt, and S. J. Cooke. 2017. To share or not to share in the emerging era of big data: perspectives from fish telemetry researchers on data sharing. Canadian Journal of Fisheries and Aquatic Sciences. https://doi. org/10.1139/cjfas-2016-0261.

Nicholls, K. W., L. Boehme, M. Biuw, and M. A. Fedak. 2008. Wintertime ocean conditions over the southern Weddell Sea continental shelf, Antarctica. Geophysical Research Letters 35: L21605. https://doi.org/10.1029/2008GL035742.

Priede, I. G. 1984. A basking shark (Cetorhinus-Maximus) tracked by satellite together with simultaneous remote-sensing. Fisheries Research 2:201-216. 
Queiroz, N., N. E. Humphries, G. Mucientes, N. Hammerschlag, F. P. Lima, K. L. Scales, P. I. Miller, L. L. Sousa, R. Seabra, and D. W. Sims. 2016. Ocean-wide tracking of pelagic sharks reveals extent of overlap with longline fishing hotspots. Proceedings of the National Academy of Sciences USA 113:1582-1587.

Raymond, B., et al. 2015. Important marine habitat off east Antarctica revealed by two decades of multi-species predator tracking. Ecography 38:121-129.

Righton, D., V. A. Quayle, S. Hetherington, and G. Burt. 2007. Movements and distribution of cod (Gadus morhua) in the southern North Sea and English Channel: results from conventional and electronic tagging experiments. Journal of the Marine Biological Association of the United Kingdom 87:599-613.

Robinson, P. W., et al. 2012. Foraging behavior and success of a mesopelagic predator in the Northeast Pacific Ocean: Insights from a data-rich species, the northern elephant seal. PLoS ONE 7:e36728. https://doi.org/10.1371/journal.pone.0036728.

Rodriguez, J. P., et al. 2017. Big data analyses reveal patterns and drivers of the movements of southern elephant seals. Scientific Reports 7:112.

Rodriguez-Cabello, C., F. de la Gandara, and F. Sanchez. 1998. Preliminary results on growth and movements of dogfish Scyliorhinus canicula (Linnaeus, 1758) in the Cantabrian Sea. Oceanologica Acta 21:363-370.

Russell, W. M. S., and R. L. Burch. 1959. The principles of humane experimental technique. Methuen, London, UK.

Schofield, G., A. Dimadi, S. Fossette, K. A. Katselidis, D. Koutsoubas, M. K. S. Lilley, A. Luckman, J. D. Pantis, A. D. Karagouni, and G. C. Hays. 2013. Satellite tracking large numbers of individuals to infer population level dispersal and core areas for the protection of an endangered species. Diversity and Distributions 19:834-844.

Semmens, J. M., N. L. Payne, C. Huveneers, D. W. Sims, and B. D. Bruce. 2013. Feeding requirements of white sharks may be higher than originally thought. Scientific Reports 3:1471. https://doi.org/10.1038/srep01471.

Sequeira, A. M. M., C. Mellin, M. G. Meekan, D. W. Sims, and C. J. A. Bradshaw. 2013. Inferred global connectivity of whale shark Rhincodon typus populations. Journal of Fish Biology 82:367-389.

Sequeira, A., et al. 2018. Convergence of marine megafauna movement patterns in coastal and open oceans. Proceedings of the National Academy of Sciences USA 115:3072-3077.

Simini, F., M. C. Gonzalez, A. Maritan, and A. L. Barabasi. 2012. A universal model for mobility and migration patterns. Nature 484:96-100.

Sims, D. W. 2003. Tractable models for testing theories about natural strategies: foraging behaviour and habitat selection of free-ranging sharks. Journal of Fish Biology 63(Supplement A): $53-73$.

Sims, D. W., J. P. Nash, and D. Morritt. 2001. Movements and activity of male and female dogfish in a tidal sea lough: alternative behavioural strategies and apparent sexual segregation. Marine Biology 139:1165-1175.

Sims, D. W., E. J. Southall, A. J. Richardson, P. C. Reid, and J. D. Metcalfe. 2003. Seasonal movements and behaviour of basking sharks from archival tagging: no evidence of winter hibernation. Marine Ecology Progress Series 248:187-196.
Sims, D. W., E. J. Southall, G. A. Tarling, and J. D. Metcalfe. 2005. Habitat-specific normal and reverse diel vertical migration in the plankton-feeding basking shark. Journal of Animal Ecology 74:755-731.

Sims, D. W., et al. 2006. Hunt warm, rest cool: bioenergetic strategy underlying diel vertical migration of a benthic shark. Journal of Animal Ecology 75:176-190.

Sims, D. W., et al. 2008. Scaling laws of marine predator search behaviour. Nature 451:1098-1103.

Soanes, L. M., J. P. Y. Arnould, S. G. Dodd, M. D. Sumner, and J. A. Green. 2013. How many seabirds do we need to track to define home-range area? Journal of Applied Ecology 50:671679.

Southall, E. J., D. W. Sims, M. J. Witt, and J. D. Metcalfe. 2006. Seasonal space-use estimates of basking sharks in relation to protection and political-economic zones in the North-east Atlantic. Biological Conservation 132:33-39.

Thums, M., S. D. Whiting, J. W. Reisser, K. L. Pendoley, C. B. Pattiaratchi, R. G. Harcourt, C. R. McMahon, and M. G. Meekan. 2013. Tracking sea turtle hatchlings - A pilot study using acoustic telemetry. Journal of Experimental Marine Biology and Ecology 440:156-163.

Thums, M., J. Fernández-Gracia, A. M. M. Sequeira, V. M. Eguíluz, C. M. Duarte, and M. G. Meekan. 2018a. How big data fast tracked human mobility research and the lessons for animal movement ecology. Frontiers in Marine Science. https://doi.org/10.3389/fmars.2018.00021.

Thums, M., J. Rossendell, M. Guinea, and L. Ferreira. $2018 b$. Horizontal and vertical movement behaviour of adult flatback turtles and spatial overlap with industrial development. Marine Ecology Progress Series 602:237-253.

Treasure, A. M., et al. 2017. Marine mammals exploring the oceans pole to pole a review of the MEOP Consortium. Oceanography 30:132-138.

Ubeda, A. J., C. A. Simpfendorfer, and M. R. Heupel. 2009. Movements of bonnetheads, Sphyrna tiburo, as a response to salinity change in a Florida estuary. Environmental Biology of Fishes 84:293-303.

Villegas-Amtmann, S., and D. P. Costa. 2010. Oxygen stores plasticity linked to foraging behaviour and pregnancy in a diving predator, the Galapagos sea lion. Functional Ecology 24:785-795.

Villegas-Amtmann, S., D. P. Costa, Y. Tremblay, S. Salazar, and D. Aurioles-Gamboa. 2008. Multiple foraging strategies in a marine apex predator, the Galapagos sea lion Zalophus wollebaeki. Marine Ecology Progress Series 363:299-309.

Wakefield, E. D., et al. 2013. Space partitioning without territoriality in gannets. Science 341:68-70.

Wearmouth, V. J., E. J. Southall, D. Morritt, R. J. Thompson, I. C. Cuthill, J. L. Partridge, and D. W. Sims. 2012. Year-round sexual harassment as a behavioural mediator of vertebrate population dynamics. Ecological Monographs 82:351-366. Weimerskirch, H., M. Louzao, S. de Grissac, and K. Delord. 2012. Changes in wind pattern alter albatross distribution and life-history traits. Science 335:211-214.

Wilson, R. P., and C. R. McMahon. 2006. Measuring devices on wild animals: What constitutes acceptable practice? Frontiers in Ecology and the Environment 4:147-154. 